DOCUMENTS

pour I'histoire
des techniques
Documents pour l'histoire des techniques

Nouvelle série

$17 \mid 1^{\text {er }}$ semestre 2009

L'invention technique et les figures de l'inventeur (XVIII $-X^{\mathrm{e}}$ siècles)

\title{
Eugène Huzar, "La Fin du monde par la science", introduction de Jean-Baptiste FRESSOZ, textes choisis et annotés par Jean-Baptiste Fressoz et François Jarrige, postface de Bruno Latour \\ Paris, $\mathrm{E}^{\oplus} \mathrm{e}, 2008,160$ pages.
}

\section{Guillaume Carnino}

\section{OpenEdition \\ Journals}

\section{Édition électronique}

URL : http://journals.openedition.org/dht/608

DOI : $10.4000 /$ dht. 608

ISSN : $1775-4194$

Éditeur :

Centre d'histoire des techniques et de l'environnement du Cnam (CDHTE-Cnam), Société des élèves du CDHTE-Cnam

\section{Édition imprimée}

Date de publication : 31 mars 2009

Pagination : 245

ISBN : 978-2-95-30779-3-3

ISSN : 0417-8726

Référence électronique

Guillaume Carnino, «Eugène Huzar, "La Fin du monde par la science", introduction de Jean-Baptiste FRESSOz, textes choisis et annotés par Jean-Baptiste Fressoz et François Jarrige, postface de Bruno Latour », Documents pour l'histoire des techniques [En ligne], 17 | $7^{\text {er }}$ semestre 2009, mis en ligne le 27 septembre 2010, consulté le 22 septembre 2020. URL : http://journals.openedition.org/dht/608 ; DOI : https:// doi.org/10.4000/dht.608

Ce document a été généré automatiquement le 22 septembre 2020.

(c) Tous droits réservés 


\title{
Eugène Huzar, "La Fin du monde par la science", introduction de Jean- Baptiste FRESSOZ, textes choisis et annotés par Jean-Baptiste Fressoz et François Jarrige, postface de Bruno Latour
}

Paris, $\grave{E}^{\circledast}$ e, 2008, 160 pages.

\author{
Guillaume Carnino
}

\section{RÉFÉRENCE}

Eugène Huzar, La Fin du monde par la science, introduction de Jean-Baptiste FRESSOZ, textes choisis et annotés par Jean-Baptiste Fressoz et François Jarrige, postface de Bruno Latour, Paris, $\grave{\mathrm{E}}^{\circledR} \mathrm{e}, 2008,160$ pages.

Eugène Huzar (1820-1890), issu de la bourgeoisie catholique parisienne et aisée, a eu un destin étrangement inverse de celui qu'il s'était imaginé. Prévoyant d'écrire pour les siècles futurs et donc condamné à subir l'incompréhension de ses contemporains (La Fin du monde par la science est publié en 1855, un mois avant l'ouverture de la première exposition universelle), Huzar est paradoxalement lu et reconnu en son temps, alors même qu'il n'était pas parvenu jusqu'à nous avant cette heureuse édition critique publiée par la jeune maison $\grave{E}^{\circledast}$ e. C'est qu'en effet, comme le précise Jean-Baptiste Fressoz dans sa judicieuse introduction, Huzar, critique de la science et du Progrès à l'heure où ces deux forces conjointes donnent libre cours à la puissance industrielle, s'imagine prêcher dans le désert à un peuple béatement converti au scientisme. En réalité, comme l'analyse très justement Fressoz, les multiples éditions de La Fin du 
monde par la science sont bien l'indice de la sensibilité et de l'inquiétude d'une époque face aux nouvelles industries et découvertes scientifiques. Plus encore, et contrairement à ce qu'une prise de conscience écologique contemporaine sur-jouée laisse entendre, les multiples révolutions industrielles ont été sciemment opérées par les capitaines d'industrie, qui, en connaissance de cause, savaient que leurs activités transformaient et corrodaient les écosystèmes (les grandes inondations de 1856, provoquées par les déforestations massives, en sont l'exemple même). Fressoz va même jusqu'à suggérer que le discours du Progrès fut en réalité catharsis du risque technologique, en ce sens que l'inconscience écologique, là où elle finit par advenir, fut en réalité le fruit d'une production administrative méthodiquement organisée.

Dès lors, on peut lire les deux ouvrages d'Huzar, La Fin du monde par la science (1855) et L'Arbre de la science (1857), partiellement reproduits dans ce livre, comme une tentative certes «messianique » (Huzar, empreint de mysticisme chrétien, multiplie les allusions prophétiques et les formules futuristes), mais qui correspond réellement aux inquiétudes de son temps. La Fin du monde par la science détaille ainsi les raisons par lesquelles la puissance a-morale qu'est devenue la science provoquera la fin de toute chose, selon un grand cycle initié par Adam et Ève en goûtant au fruit métaphorique et défendu de l'Arbre de la science. D'où le titre de son second ouvrage, dans lequel Huzar détaille, explications mythologiques et anecdotes industrielles à l'appui, le pourquoi des méfaits potentiels de la science. Car, dans la lignée chrétienne à laquelle Huzar puise son inspiration, le péché originel marque l'humanité depuis le début du cycle actuel (selon lui commencé il y a environ 6000 ans). Bien que la teinte religieuse du discours puisse parfois surprendre, certaines réflexions apparaissent comme particulièrement lucides, et, au risque d'anachronisme, sembleraient même parfois concerner le $\mathrm{XXI}^{\mathrm{e}}$ siècle. Sans doute faut-il y voir, bien plus que la marque d'un prophète injustement oublié, la continuité de notre monde avec celui produit dès les débuts de l'ère industrielle. Le propos, bien évidemment parfois désuet, reste néanmoins singulier. À ne pas manquer donc.

3 Seul réel point faible du livre, sur lequel il convient de ne pas s'appesantir tant il est normal de solliciter un nom rebattu afin de donner davantage de visibilité à un ouvrage a priori confidentiel, la postface de Bruno Latour qui, sous couvert d'humour facile et de relativisme bon teint, amollit le propos général du livre en accentuant le côté atypique de Huzar aux yeux d'un contemporain - ce qui a, au contraire du propos introductif informé et analytique de Fressoz, pour effet paradoxal (et ce, d'autant plus chez Latour) de pousser l'idée d'évolution technoscientifique aux limites de la naturalisation.

\section{AUTEURS}

\section{GUILLAUME CARNINO}

EHESS-Centre Alexandre Koyré, CDHTE-Cnam 